\title{
Stability of GO Modified by Different Dispersants in Cement Paste and Its Related Mechanism
}

\author{
Wu-Jian Long *(1), Changle Fang, Jingjie Wei and Haodao Li \\ Guangdong Provincial Key Laboratory of Durability for Marine Civil Engineering, Shenzhen Durability Center \\ for Civil Engineering, College of Civil Engineering, Shenzhen University, Shenzhen 518060, China; \\ 2150150420@email.szu.edu.cn (C.F.); 2150150416@email.szu.edu.cn (J.W.); lihaodao2017@email.szu.edu.cn (H.L.) \\ * Correspondence: longwj@szu.edu.cn; Tel.: +86-755-2691-7292; Fax: +86-755-2653-4021
}

Received: 20 April 2018; Accepted: 17 May 2018; Published: 18 May 2018

\begin{abstract}
Graphene oxide (GO) is a potential material to be used as a nano-reinforcement in cement matrix. However, a prerequisite for GO to fulfill its function in the cement matrix is homogeneous dispersion. In this study, the effects of three different dispersing agents (DAs), including polycarboxylate-based high range water reducer (P-HRWR), naphthalene-based high range water reducer (N-HRWR), and air entraining agent (AEA) on the dispersion of $\mathrm{GO}$ in aqueous solution, simulated concrete pore solution (SCPS), and suspension of cement pastes were sequentially investigated. Results showed that the dispersion effect of GO in aqueous solutions was improved with different DAs. However, the homogeneous dispersion of GO in aqueous solution re-agglomerated in SCPS and suspension of cement pastes. It was concluded that as the cement content and $\mathrm{pH}$ of aqueous solutions increased, GOs re-agglomerated and precipitated in an alkaline solution. A possible mechanism was proposed in this study and it was believed that electrostatic interactions and steric hindrance provided by the P-HRWR further made GOs stable in aqueous solutions. The ions and $\mathrm{pH}$ of cement pastes increased with the increasing amount of cement, which caused the separation of P-HRWR from GOs. Therefore, GOs were re-agglomerated and absorbed on the surface of the cement particles, resulting in GOs sedimentation.
\end{abstract}

Keywords: graphene oxide; dispersing agents; agglomeration; cement paste; mechanism

\section{Introduction}

Modern concrete technology is shifting towards a high-performance application with a desire to be sustainable [1,2]. Nano-materials have shown to improve the micro-structure and comprehensive performance of cement-based composites [3-6]. Moreover, several studies on self-sensing cement composites which uses nanocomposites have also been reported [7-9]. Thus, nano-modified cement-based materials are the main technical ways for developing ultra-high-performance concrete (UHPC). However, due to small particle size, large specific surface area and high surface energy of nano-materials, the use of nano-materials in cement matrix causes high water consumption and agglomeration [10-13]. In recent years, the development of nano-carbon-based materials (carbon nano-tubes, graphene, graphene oxide, etc.) and zero-dimensional nanoparticles (nano- $\mathrm{SiO}_{2}$, nano- $\mathrm{CaCO}_{3}$, nano- $\mathrm{Al}_{2} \mathrm{O}_{3}$, etc.) has demonstrated that the microstructure and mechanical performance of concrete can be improved significantly [14-16].

Graphene oxide (GO) is characterized by a high aspect ratio and good interface contact with cement matrix $[17,18]$. GO can further facilitate the generation of hydration products and reduce the porosity of hardened cement pastes allowing for improved strength, toughness, and durability of the cement-based materials $[19,20]$. However, a high amount of GO in cement matrix does not necessarily give a better performance because an excessive amount of GO results in a loss of mechanical 
performance [21]. In addition, a high alkalinity and high ionic strength of concrete can result in agglomeration of GO [22].

The uniform dispersion and distribution of GO in cement pastes is essential to fulfill the function of GO. When GO is non-uniformly dispersed, their sizes may not be closer to those of calcium silicate hydrate (C-S-H) gel, and thus cement matrix at the nano-scale could not be improved [2]. In current studies, the uniform dispersion of GO is achieved by physical and chemical methods [23-26]. The common physical dispersion methods include ultrasonication, ball milling, and high shear mill [23]. The chemical dispersion methods usually use surfactants for surface activation, such as polycarboxylate-based high range water reducer (P-HRWR) and naphthalene-based high range water reducer (N-HRWR) [24-26].

Currently, most studies focus on the dispersion of GO in aqueous solutions $[19,27,28]$, and rarely mention its dispersion or re-agglomeration after being added into cement pastes. However, a homogeneous dispersion of GOs in aqueous solutions may not be a guarantee of a uniform dispersion in cement pastes $[29,30]$. Due to the complex electrolyte, the dispersion and stability of GO in the pore solution of concrete can be very different from those in aqueous solutions. After studying the dispersion conditions of carbon nano-fibers under different dispersing agents and different $\mathrm{pH}$, Stephen et al. [24] pointed out that, no matter when the carbon nano-fibers were dispersed in an aqueous solution or a simulated concrete pore solution (SCPS), P-HRWR always had the optimum dispersion effect for carbon nano-fiber in comparison to N-HRWR and air entraining agent (AEA). P-HRWR further weakened the re-agglomeration effect of carbon nanotube fiber in hardened pastes. The study done by Kaili et al. [31] showed that N-HRWR had a better dispersion effect for graphene. When the mass of N-HRWR and graphene were the same, the most stable dispersion was witnessed in aqueous solutions. Therefore, different types of water reducer and concentrations exert different influences on the dispersion of nanocarbon-based materials in aqueous solutions. In addition, the change of $\mathrm{pH}$ in the process of cement hydration also influences the dispersion of GO. It is known that the $\mathrm{pH}$ of the pore solution of concrete is 12.6 to 13.5 [32,33]. Meanwhile, GO in pore solutions with high $\mathrm{pH}$ and high ionic strength prefers to yield agglomeration and sedimentation [32,34].

Based on the abovementioned, this paper adopts three different dispersing agents (P-HRWR, N-HRWR, and AEA) and three different GO to DA mass ratios (1:1, 3:1, and 9:1) to investigate the dispersion, re-agglomeration and related mechanisms of GO in aqueous solutions, SCPS and suspension of cement pastes. Understanding the behavior of GOs in aqueous solutions and the relationship between the relative re-agglomeration state of GOs in SCPS and in cement pastes is critical for the development of reliable GO cement composites.

\section{Materials and Methods}

\subsection{Raw Materials}

\subsubsection{Graphene Oxide (GO)}

The suspension of GO $(3 \mathrm{~g} / \mathrm{L})$ was prepared by dispersing the graphite oxide powder into water with probe sonication. Graphite oxide was purchased from the Sixth Element Ltd. (Changzhou, China) and the properties were given in Table 1. Based on the previous study [35], the power and time of ultrasonic were selected $25 \mathrm{~Hz}, 400 \mathrm{~W}$ and $2 \mathrm{~h}$ ( $2 \mathrm{~s}$ on, $4 \mathrm{~s}$ off), respectively.

Table 1. The properties of graphite oxide.

\begin{tabular}{lcccccc}
\hline Appearance & $\begin{array}{c}\text { Solid Content } \\
\text { (mass \%) }\end{array}$ & pH & Viscosity & $\begin{array}{c}\text { Absorbance Ratio } \\
\text { A230/A600 }\end{array}$ & Carbon (\%) & $\begin{array}{c}\text { Molar Ratio } \\
\text { (O/C) }\end{array}$ \\
\hline Brown paste & $43 \pm 1$ & $\geq 1.2$ & $\geq 2000$ & $\geq 45$ & $47 \pm 5$ & $0.6 \pm 1$ \\
\hline \multicolumn{7}{c}{ Note: “O": oxygen atom; “C”: carbon atom. }
\end{tabular}


The GO sample was characterized using atomic force microscope (AFM, type ICON-PT-PKG, Bruker, Fremont, CA, USA), transmission electron microscopy (TEM, type JEM-1230, NIPPON TEKNO company, Osaka, Japan), as illustrated in Figure 1a-c. AFM image (Figure 1a) showed that the used GO sheets exhibited irregular shapes with a dimension of about $0.1 \mu \mathrm{m}$ and a thickness of about $1.3 \mathrm{~nm}$. TEM (Figure 1c) image demonstrated that GO was an almost transparent nanosheet with various wrinkles and folds.
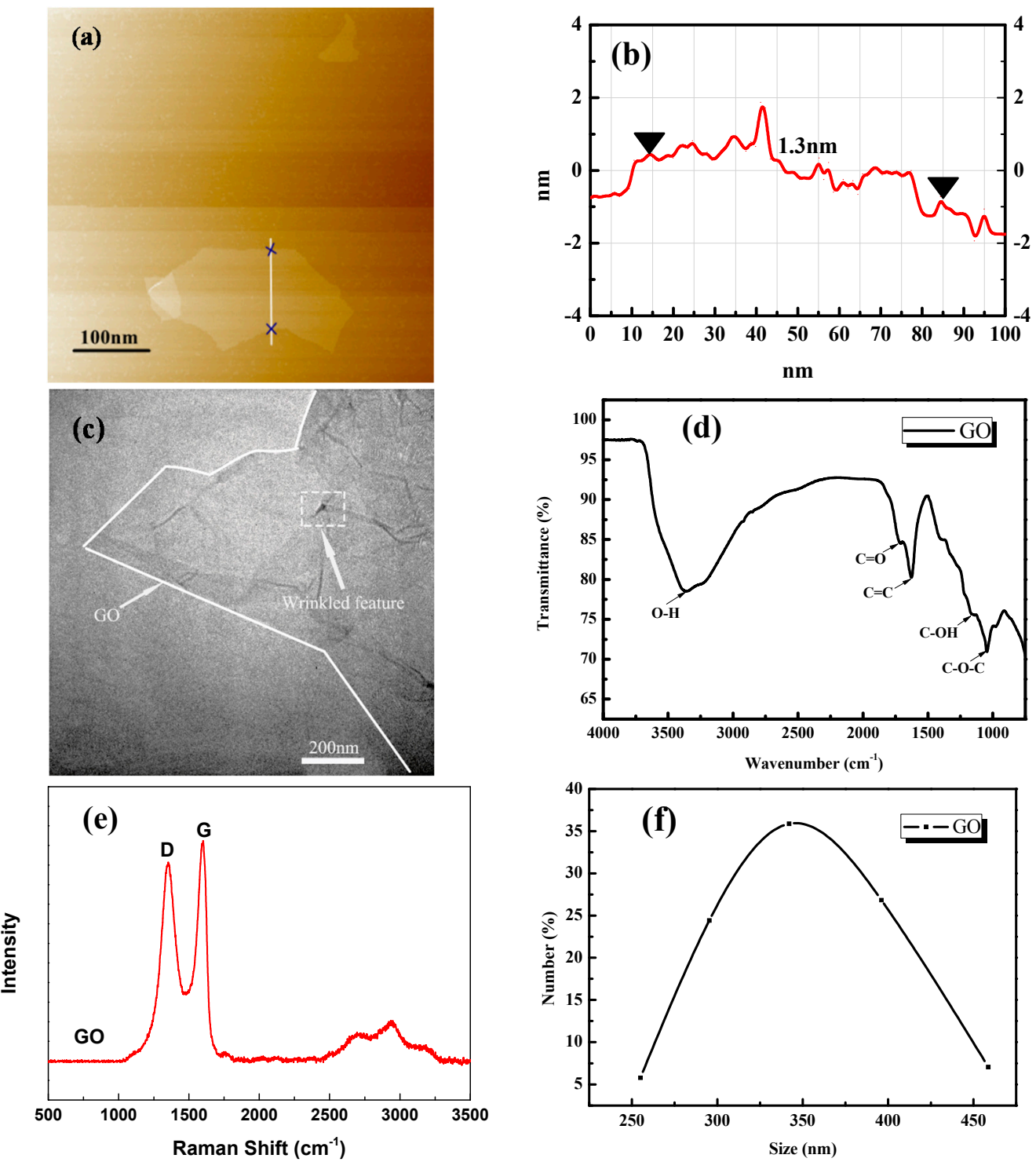

Figure 1. The characterization of GO (a) AFM image; (b) AFM spectra; (c) TEM Image; (d) FTIR transmittance spectra; (e) Raman spectra; (f) LPSA image.

The oxygen-carbon groups of GO were tested with Fourier transform infrared spectroscopy (FTIR, Perkin Elmer Spectrum 100, Perkin Elmer Company, Waltham, MA, US), as shown in Figure 1d. The bands that appeared at about $3400 \mathrm{~cm}^{-1}$ for GO were assigned to the $-\mathrm{OH}$ stretching vibration because of the existence of hydrolytic groups and residual water [36]. An absorption peak for the $\mathrm{C}=\mathrm{C}$ stretch was observed at $1634 \mathrm{~cm}^{-1}$ and peaks at $1720 \mathrm{~cm}^{-1}$ were also seen in carbonyl groups $(\mathrm{C}=\mathrm{O})$, in agreement with the peak at 1058 in the $-\mathrm{COOH}$ group indicating alkoxy $\mathrm{C}-\mathrm{O}$ stretching $[37,38]$. These oxygen functionalities endowed GO with a high hydrophilicity, thus making it easily dispersed in the aqueous cement pastes. GO took up a large specific surface area, which provided a significantly 
large contact area with the cement materials. The chemical composition of GO was consisted of $49.6 \mathrm{wt} \% \mathrm{C}, 2.1 \mathrm{wt} \% \mathrm{H}$ and $48.3 \mathrm{wt} \% \mathrm{O}$ (by difference), respectively.

The Raman spectrum (RM 3000 Micro-Raman system (Bruker, Fremont, CA, USA)) of GO was also conducted, as shown in Figure 1e. There were two main Raman shifts characterized by carbon nano-materials ranging from 1200 to $1700 \mathrm{~cm}^{-1}$. The first band at $1620 \mathrm{~cm}^{-1}$ could be attributed to the graphite mode (G band), while the second band at $1380 \mathrm{~cm}^{-1}$ could be attributed to diamondoid mode (D band) [39]. In comparison with graphite, the ID/IG mass ratio was observed to rise, with the presence of disordered structure in graphite arising from different functional groups in the structure $[40,41]$.

The particle size distribution of well dispersed GO was characterized by laser particle size analyzer (LPSA, Mastersizer 2000, Malvern Panalytical, City of Malvern, UK), as shown in Figure 1f. The particle size distribution ranged from $255 \mathrm{~nm}$ to $459 \mathrm{~nm}$ and mostly distributed in $350 \mathrm{~nm}$.

\subsubsection{Dispersing Agents (DAs)}

A sulfonated-naphthalene condensate high-range water reducer (N-HRWR) type of Sika KS-20, a polycarboxylate-based HRWR (P-HRWR) type of Sika TMS-YJ-1, and an air-entraining admixture (AEA) of BASF MicroAir (BASF SE, Ludwigshafen, Germany) were employed, which conformed to the requirements of GB 50119-2013 [42]. P-HRWR was blended by the type of RMC-3 and CP-WRM50 with a ratio of $1 / 4$. The characteristics of DAs are listed in Table 2 . These three different DAs were thus selected for comparisons based on their different mechanisms of action and known compatibility with cement hydration. The N-HRWR is an anionic surfactant that works through electrostatic repulsion by providing particles with a highly negative surface charge through its adsorption onto their surface, causing their mutual repulsion [43]. The P-HRWR is a polymer surfactant that works through a dual mechanism of electrostatic repulsion and steric stabilization in which the long molecules of the organic polymer wrap around the particles to prevent their aggregation by physically precluding them to approach each other $[43,44]$. The AEA is a modified resin acid compound-based anionic surfactant that lowers the surface tension of water [45]. HRWRs are frequently used in concrete technology to improve the workability of cementing materials system, and AEAs are widespread practice to increase freeze-thaw and scaling resistances.

Table 2. The characteristics of DAs.

\begin{tabular}{ccccc}
\hline Type & Aspect & Solid Content, $\%$ & pH & Recommended Content \\
\hline RMC-3 & Dark-brown liquid & 49.98 & $5-6$ & $0.5 \%-1.5 \%$ \\
CP-WRM50 & Slight-yellow liquid & 50.79 & $4-5$ & $0.75 \%-1.5 \%$ \\
KS-20 & Yellow brown solid & 95 & $6-7^{\mathrm{a}}$ & $0.03 \%-0.1 \%$ \\
K12 & White solid & 96 & $7-8^{\mathrm{a}}$ & \\
\hline
\end{tabular}

Note: ${ }^{\text {a }}$ solution with the mass concentration of $5 \%$.

\subsubsection{Cement}

Type I ordinary Portland cement, conforming to the requirements of Chinese Standard GB 175 [46], was used as the base material in this research. Figure 2 shows the particle size distribution of cement and the chemical composition and physical properties of cement is detailed in Table 3. 


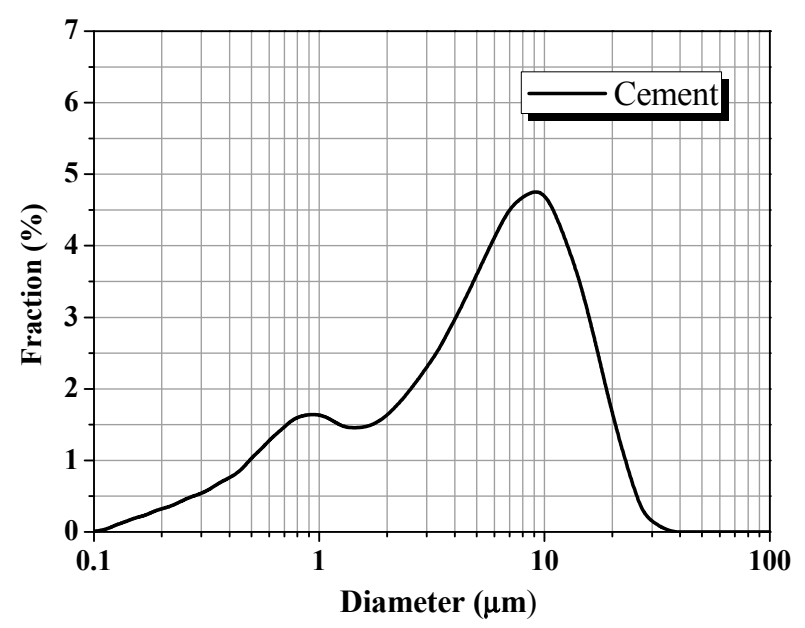

Figure 2. Distribution of particle diameter of cement.

Table 3. Chemical compositions (\% by mass) and physical properties of cement.

\begin{tabular}{|c|c|c|c|c|c|c|c|c|c|}
\hline Composition & $\mathrm{CaO}$ & $\mathrm{SiO}_{2}$ & $\mathrm{Al}_{2} \mathrm{O}_{3}$ & $\mathrm{Fe}_{2} \mathrm{O}_{3}$ & $\mathrm{MgO}$ & $\mathrm{SO}_{3}$ & $\mathrm{f}-\mathrm{CaO}$ & $\mathrm{Na}_{2} \mathrm{O}$ & LOI \\
\hline Content (\%) & 64.65 & 21.88 & 4.49 & 3.45 & 2.36 & 2.44 & 0.28 & 0.51 & 1.31 \\
\hline Fineness $(0.08 / \%)$ & \multicolumn{3}{|c|}{$\begin{array}{l}\text { Specific Surface Area } \\
\left(\mathrm{m}^{2} / \mathrm{kg}\right)\end{array}$} & \multicolumn{2}{|c|}{$\begin{array}{l}\text { Density } \\
\left(\mathrm{g} / \mathrm{cm}^{3}\right)\end{array}$} & \multicolumn{2}{|c|}{$\begin{array}{l}\text { Setting Times } \\
\text { (min) }\end{array}$} & \multicolumn{2}{|c|}{ Stability } \\
\hline \multirow{2}{*}{0.8} & \multirow{2}{*}{\multicolumn{3}{|c|}{344}} & \multirow{2}{*}{\multicolumn{2}{|c|}{3.15}} & Final & Initial & \multirow{2}{*}{\multicolumn{2}{|c|}{ Qualified }} \\
\hline & & & & & & 130 & 205 & & \\
\hline
\end{tabular}

\subsection{Preparation of GO Suspensions}

GO suspensions were prepared to determine the adequate dispersion conditions with regards to DA type as well as DA to GO mass ratio. GO suspensions were also employed to monitor the stability of the dispersions as a function of $\mathrm{pH}$ in dynamic conditions close to those obtained during cement mixing.

\subsubsection{DA Type and DA to GO Mass Ratio}

In order to achieve the homogeneous and stable dispersions of GO, the effects of DA type (N-HRWR, P-HRWR, and AEA) and DA to GO mass ratios (1:1, 3:1, and 9:1) on GO dispersion in three solutions were investigated, respectively. These three solutions were aqueous solution, SCPS, and suspension of cement pastes. The DA to GO mass ratios of 1:1, 3:1, and 9:1 were chosen based on preliminary results, consistent with the limited data found in the literature [47-50], which suggested DA to carbon nano-material mass ratios ranged from 4:1 to 8:1 for effective dispersion.

In order to analyze the UV-Vis absorbance of the GO solutions, the GO aqueous solution was used at a concentration of $0.03 \mathrm{~g} / \mathrm{L}$, which was obtained by 100 times the dilution of well-dispersed $3 \mathrm{~g} / \mathrm{L} \mathrm{GO}$ aqueous solution.

Due to the functions of different dispersing agents, GO exhibited diverse stability by adding different dispersing agents. This stability can then be used to present speed of re-agglomeration and sedimentation of GO over time. When GO in the solution began to precipitate, the concentration of GO solutions decreased, and then the absorbance of GO decreased as well. By analyzing how the absorbance of the upper solutions differed over time, the effect of different DAs on the dispersing effects of GO in aqueous solutions could be observed. Similarly, the dispersing effects of GO in aqueous solution can then be examined with various DAs to GO mass ratio. The specific surface area of GO suspension after $30 \mathrm{~min}$ of resting was also tested in order to further analyze the influences of different dispersant types and concentration on the dispersing effects of GO in aqueous solutions. 
Table 4 illustrates DA to GO mass ratios and the corresponding DA to solution mass ratios for different GO concentration.

Table 4. DAs to GO mass ratios and corresponding DA to solution mass ratios.

\begin{tabular}{cccc}
\hline Sample & GO $(\mathbf{g})$ & DAs $(\mathrm{g})$ & Water $(\mathrm{g})$ \\
\hline pGO & 0.03 & 0 & 999.97 \\
GO-N-1 & 0.03 & N-HRWR, 0.03 & 999.97 \\
GO-N-3 & 0.03 & N-HRWR, 0.09 & 999.97 \\
GO-N-9 & 0.03 & N-HRWR, 0.27 & 999.97 \\
GO-A-1 & 0.03 & AEA, 0.03 & 999.97 \\
GO-A-3 & 0.03 & AEA, 0.09 & 999.97 \\
GO-A-9 & 0.03 & AEA, 0.27 & 999.97 \\
GO-P-1 & 0.03 & P-HRWR, 0.03 & 999.97 \\
GO-P-3 & 0.03 & P-HRWR, 0.09 & 999.97 \\
GO-P-9 & 0.03 & P-HRWR, 0.27 & 999.97 \\
\hline
\end{tabular}

Optimum DA to GO mass ratios were chosen depending on the best dispersion of GO aqueous solution. Only this optimum DA to GO mass ratio was then considered when GO were dispersed in SCPS and cement pastes. The SCPS presents the typical chemical environment of hydrating Portland cement pastes at an age of $2 \mathrm{~h}$ with a composition as reported in Ref. [51]. Occurrence of GO agglomeration at this stage will most likely remain at later stages of hydration during the hardening process. The SCPS was prepared with deionized water and $20.2 \mathrm{~g} / \mathrm{L}$ potassium hydroxide $(\mathrm{KOH}), 1.2 \mathrm{~g} / \mathrm{L}$ sodium hydroxide $(\mathrm{NaOH})$, and $21.4 \mathrm{~g} / \mathrm{L}$ calcium sulfate hemihydrate $\left(\mathrm{CaSO}_{4} \cdot \frac{1}{2} \mathrm{H}_{2} \mathrm{O}\right)$, resulting in a measured $\mathrm{pH}$ about 13.3 .

\subsubsection{Effect of Cement Addition and Solution $\mathrm{pH}$}

Aqueous solution suspensions of GOs (0.03 g/L) at different DA to GO mass ratios (1:1, 3:1, and 9:1) were prepared. To account for the dynamic conditions obtained during cement mixing, cement powder was added to the suspensions in $0.34 \mathrm{~g}$ increments per $100 \mathrm{~mL}$ of suspension to cover a solution $\mathrm{pH}$ ranging from about 7 ( $\mathrm{pH}$ of the GO aqueous solution with $\mathrm{DA}$ ) to 11.5 to 12 ( $\mathrm{pH}$ of cement pastes). The stability of the dispersion as a function of $\mathrm{pH}$ was visually monitored.

\subsection{Testing Methods}

\subsubsection{UV-Vis Absorption Spectrum}

Ultraviolet-visible spectrum can be generated when ultraviolet light, visible light and near-infrared light are absorbed by materials. The spectrum can be used to analyze the absorbance of the materials. The absorption degree is proportional to the concentration of the materials. The larger the absorbance of the solution, the more homogenous dispersion of GO in the solution [52-54]. As an indirect method, UV-Vis measures the degree of dispersion of GO in a non-quantitative manner. The dispersion of the materials are quantitatively reflected by the spectrum and better dispersion measured means higher absorbance. In this work, Lambda $750 \mathrm{UV}-\mathrm{Vis}$ spectrophotometer (PerkinElmer, Waltham, MA, USA, see in Figure 3) is used to evaluate the adsorption performance of GO aqueous solution. 


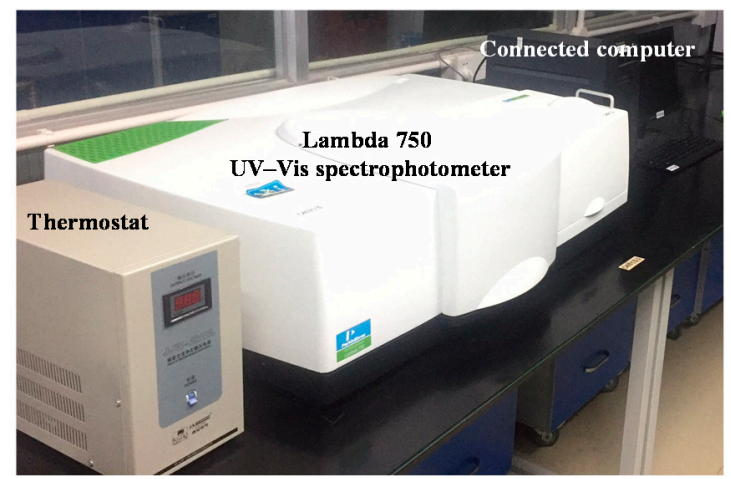

Figure 3. Lambda $750 \mathrm{UV}-$ Vis spectrophotometer.

\subsubsection{Characterization of the Specific Surface Area of GO}

Low Field Nuclear Magnetic Resonance (LF-NMR, PQ001 type, Niumag Company, Shanghai, China) can measure and analyze the specific surface area of particles in a suspension state. When the particles are in the state of suspension, a layer of water molecules with a thickness of $L$ is adsorbed on the surface of particles. It was called the adsorption water and outside the molecular layer of which was the free water. The activity of $\mathrm{H}$ proton in the adsorption water and that of free water are very different, making a relaxation time of the adsorbed water far less than free water. This difference can reflect the amount of adsorbed solution on the surface of the particles and thus the wet specific surface area of the particles is derived.

LF-NMR characterization of GOs dispersions was performed by means of a particle size surface area analyzer given in Figure 4. The samples were vacuumed at 3 mTorr and heated to $80{ }^{\circ} \mathrm{C}$ for $5 \mathrm{~min}$ prior to analysis. The testing process was divided into two steps: first a solvent (distilled water) measurement was conducted, followed by a sample measurement.

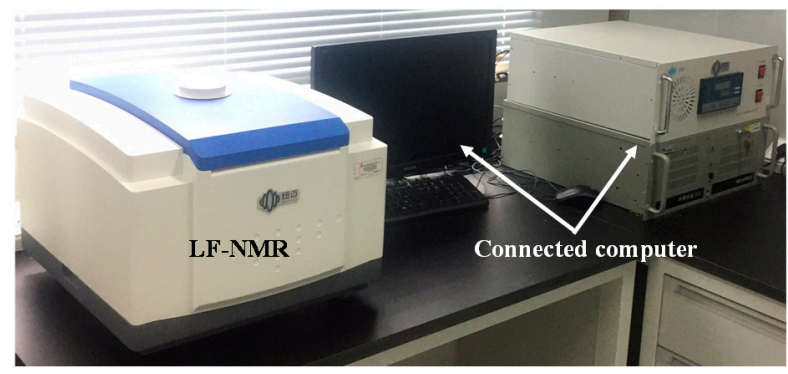

Figure 4. Particle size surface area analyzer.

\section{Results and Discussion}

\subsection{Dispersion State of GO in Aqueous Solutions}

\subsubsection{Selection of Wavenumber}

Figure 5 presents the absorbance curves of different DAs at the same concentration $(0.03 \mathrm{~g} / \mathrm{L})$ with wavenumbers of 200 to $800 \mathrm{~nm}$ (the wavenumber of ultraviolet light spectrum is under $400 \mathrm{~nm}$, the wavenumber of visible light spectrum is from 400 to $780 \mathrm{~nm}$ and the wavenumber from 780 to $800 \mathrm{~nm}$ is near-infrared spectrum). Unstable absorption could be observed in the ultraviolet area with the characteristic peaks of each DA. Two peaks of N-HRWA appeared at $245 \mathrm{~nm}$ and $293 \mathrm{~nm}$; two peaks of P-HRWR occurred at $219 \mathrm{~nm}$ and $284 \mathrm{~nm}$; one peak of AEA was at $281 \mathrm{~nm}$. These three DA solutions remained stable and exhibited absorption within the range of 400 to $800 \mathrm{~nm}$. Based on the above analysis, while conducting the absorbance test of aqueous suspensions of GO, the excitation 
wavenumber was set to $650 \mathrm{~nm}$, which should help eliminate the absorption influence of DAs and ensure the change of absorbance was due to dispersion of GO [53].
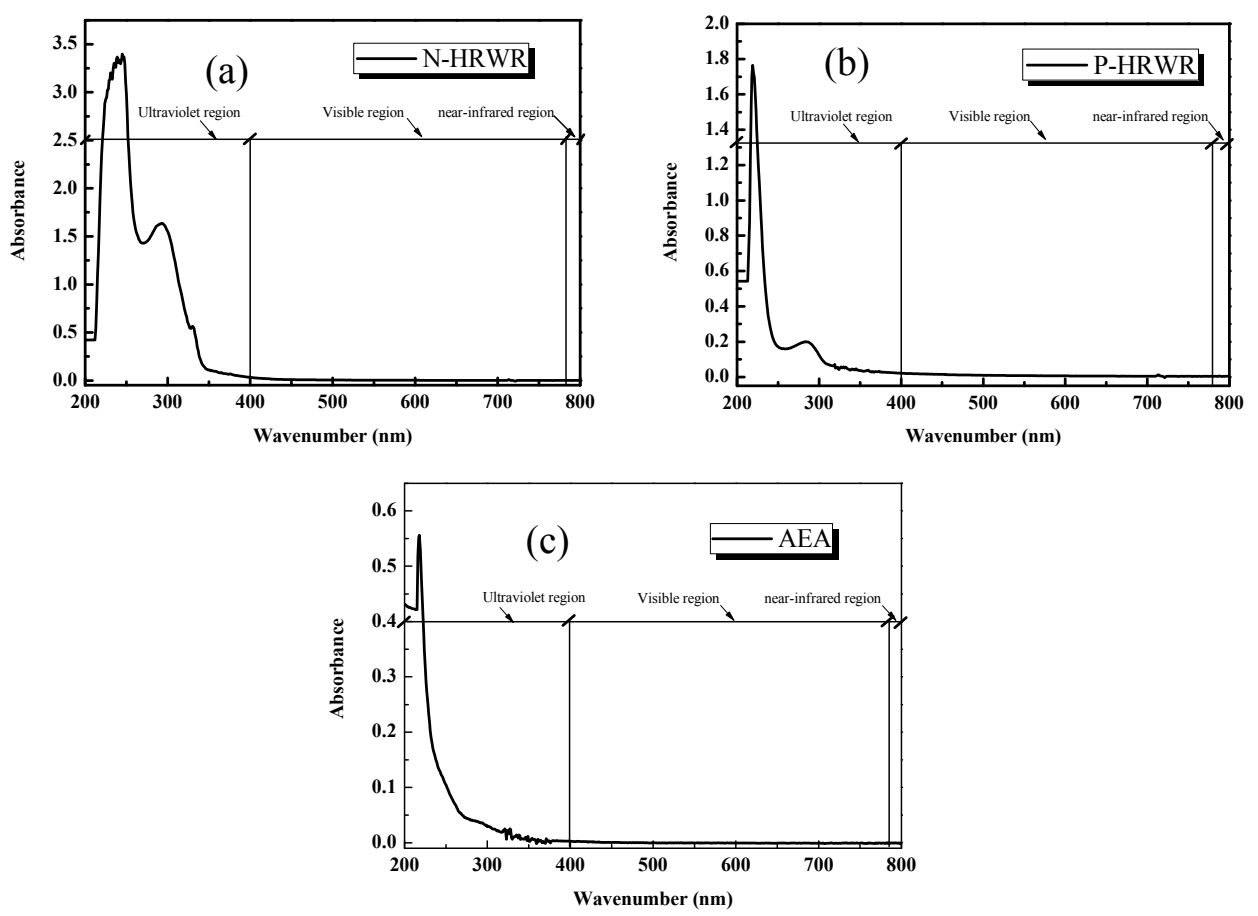

Figure 5. Typical UV-Vis absorption spectra of different DAs solution: (a) N-HRWR; (b) P-HRWR; (c) AEA.

\subsubsection{Effect of DA Types}

Figure 6 shows the GO solution with the different DAs and different DA to GO mass ratios after sonication. It can be seen that, after adding N-HRWR and P-HRWR into the aqueous solution of GO, the originally clear aqueous solution immediately became turbid. In the case of AEA to GO mass ratio, the clear aqueous solution did not turn turbid until the ratio reached its maximum value of 9:1. To further determine the influence of different dispersing agent types on the dispersion of GO in aqueous solutions, an UV-Vis spectrophotometer was used to test solutions of different dispersion types, as shown in Figure 7. As shown in Figure 8, the three dispersing agents were all able to facilitate the dispersion of GO in aqueous solutions. When N-HRWR: GO =3:1, the absorbance of the aqueous solution of GO at $650 \mathrm{~nm}$ exhibited the maximum value of 0.098 ; when P-HRWR: $\mathrm{GO}=1: 1$, the absorbance of the aqueous solution of $\mathrm{GO}$ at $650 \mathrm{~nm}$ exhibited a maximum value of 0.123 ; when $\mathrm{AEA}: \mathrm{GO}=9: 1$, the absorbance of the aqueous solution of $\mathrm{GO}$ at $650 \mathrm{~nm}$ reached its maximum value of 0.211 . Thus, the higher the absorbance of the solution, the more uniform the dispersion of GO in the solution [52,53]. Thus, when AEA: GO = 9:1, AEA, among the three dispersing agents, realized the optimum dispersion for $\mathrm{GO}$ in the aqueous solution. 

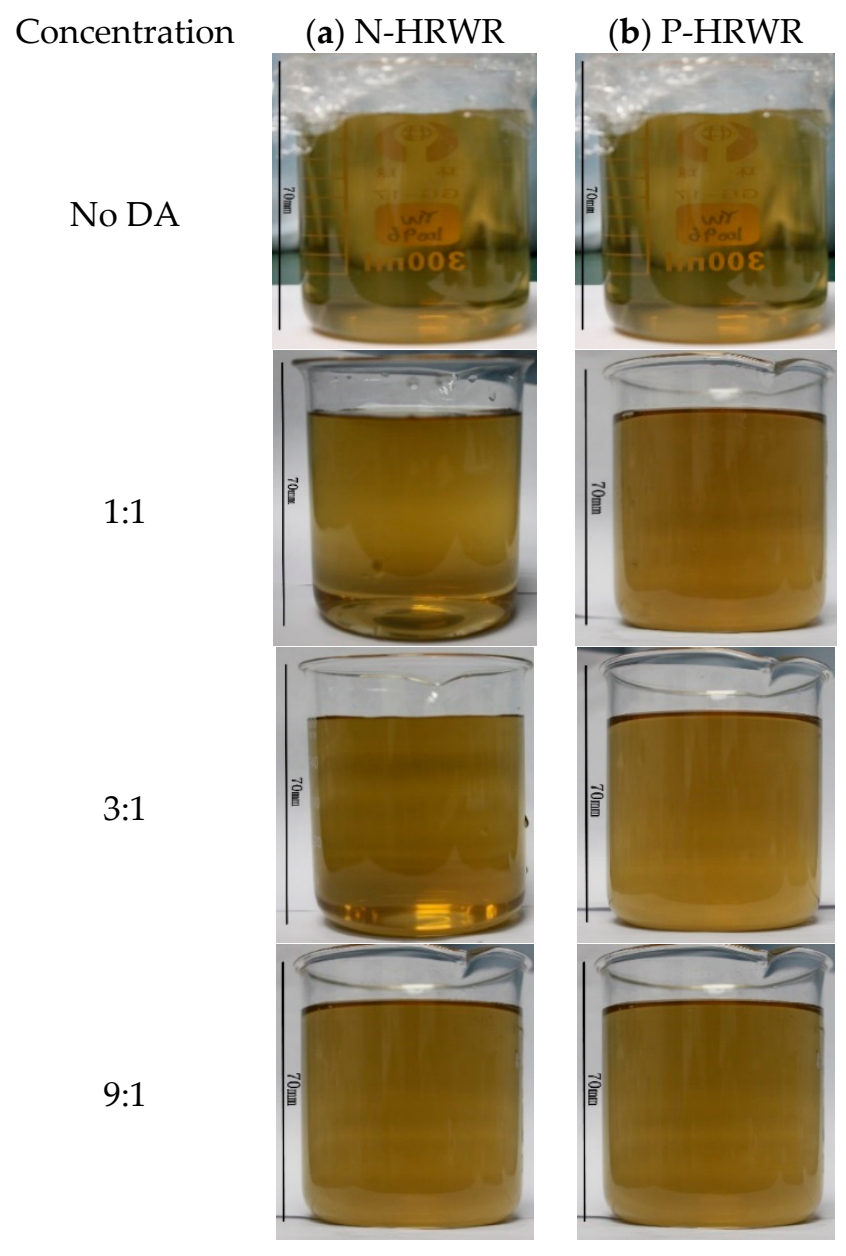

(c) AEA

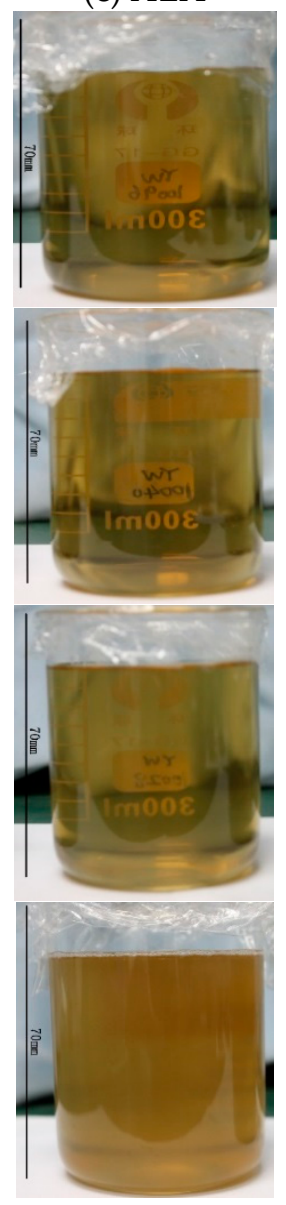

Figure 6. Dispersion state of GO suspensions $(0.03 \mathrm{~g} / \mathrm{L})$ in water with different DAs and concentration: (a) N-HRWR; (b) P-HRWR; (c) AEA.

\subsubsection{Effect of DA Concentrations}

As shown in Figure 7, after adding N-HRWR and P-HRWR into the aqueous solution of GO, the originally clear aqueous solution immediately became turbid and the increase of the concentrations of N-HRWR and P-HRWR in the aqueous solution of GO remained turbid. However, the aqueous solution of GO was always stable, and did not present any agglomeration or sedimentation of GO. When AEA: GO was 1:1 or 3:1, the aqueous solution of GO still remained in a clear state; however, when AEA: GO was increased to 9:1, the originally clear aqueous solution became turbid. According to the results of Figure 8, with the increase of N-HRWR to GO mass ratio from 1:1, 3:1, to 9:1, the absorbance of the aqueous solution of GO remained unchanged. That is, increasing N-HRWR to GO mass ratio provided no benefit for the dispersion of GO in the aqueous solution. With the increase of P-HRWR to GO mass ratio from 1:1 to 3:1, the absorbance of the aqueous solution of GO gradually declined, and increasing from 3:1 to 9:1 the absorbance of the aqueous solution of GO remained unchanged. Thus, within a certain range, increasing P-HRWR to the GO mass ratio would be detrimental to the dispersion of GO in the aqueous solution. The optimum P-HRWR to GO mass ratio would be 1:1. With the increase of AEA to GO mass ratio from 1:1, 3:1 to 9:1, the absorbance of the aqueous solution of GO gradually increased. Thus, increasing AEA to GO mass ratio would be conducive to the dispersion of GO in the aqueous solution and the optimum AEA to GO mass ratio would be 9:1. 

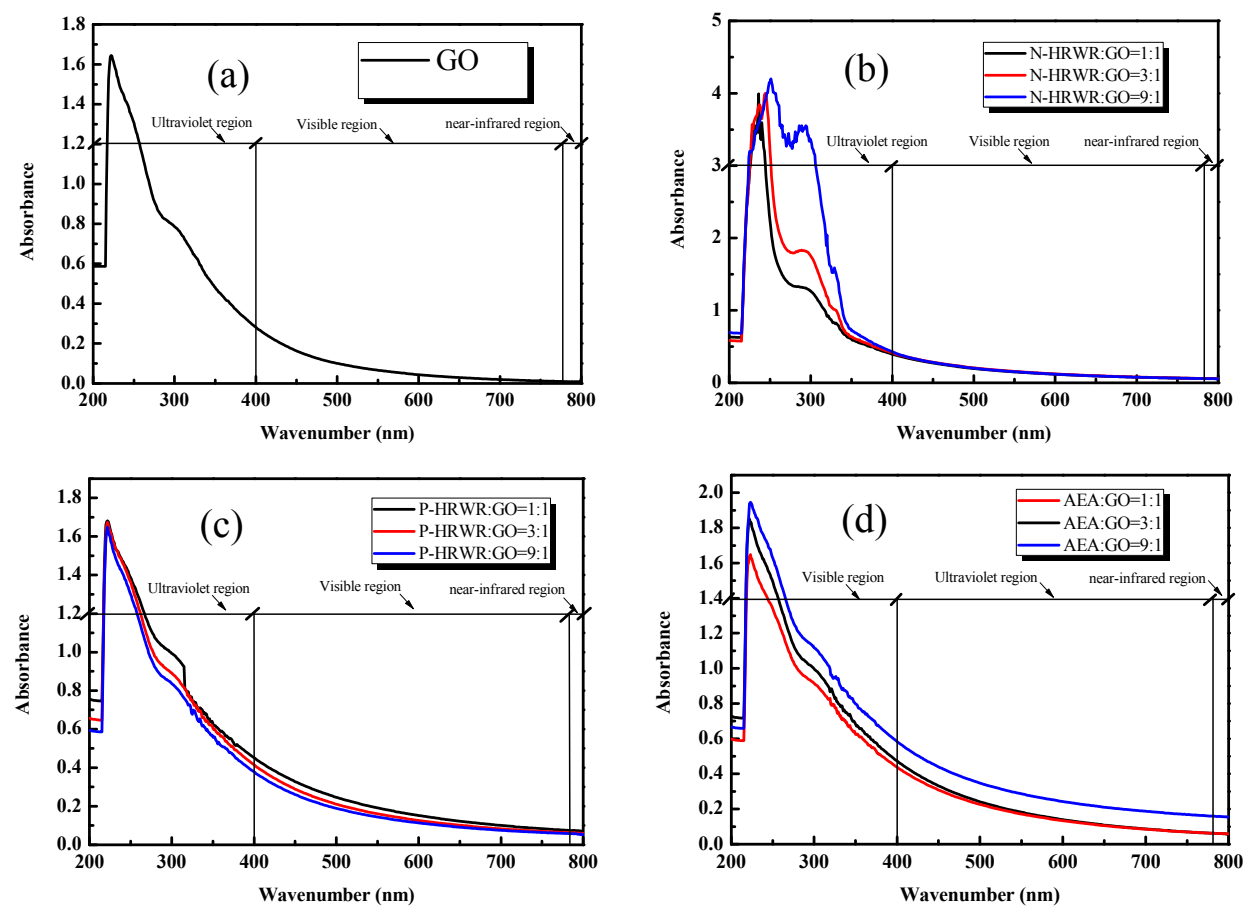

Figure 7. Absorption spectra of GO solution with different DAs and concentration: (a) without DAs; (b) with N-HRWR; (c) with P-HRWR; (d) with AEA.

As shown in Figure 8 and Table 5, the greater the absorbance of GO, the larger the specific surface area of the GO in the solution. It shows that the dispersing agents can effectively prevent the re-agglomeration of GO in the aqueous solution. It was difficult to distinguish the re-agglomeration of GO by visual inspection when the GO aqueous solution was rested for $30 \mathrm{~min}$.

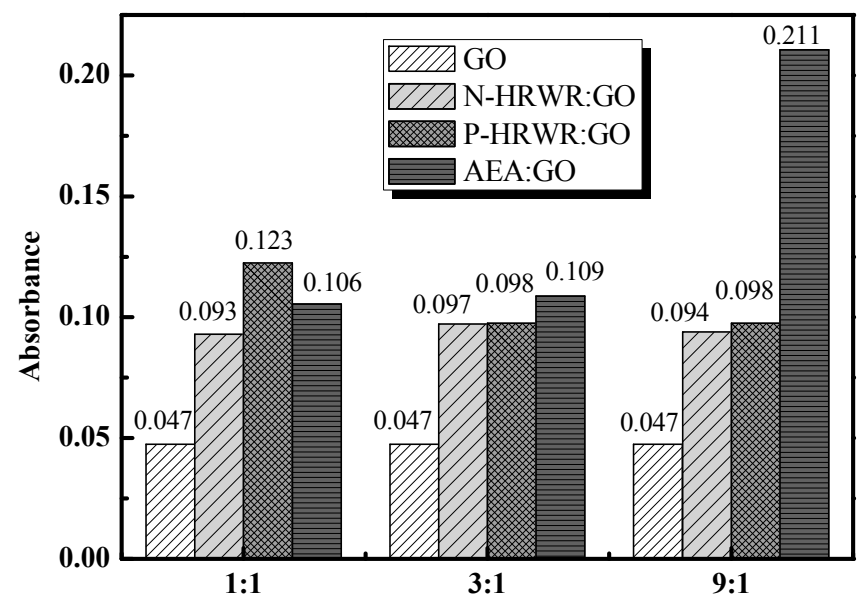

Figure 8. Different absorbance on 650nm of GO solution with different DAs and concentration. 
Table 5. Surface parameters and particle size characteristics of GO in aqueous solution.

\begin{tabular}{|c|c|c|c|c|c|}
\hline Sample & $\begin{array}{l}\text { Sample Style } \\
\text { (Diameter) }\end{array}$ & Solvent & $\begin{array}{c}\text { Particle Weight } \\
\text { Concentration }\end{array}$ & $\begin{array}{c}\text { Density of Particle } \\
(\mathrm{g} / \mathrm{mL})\end{array}$ & $\begin{array}{c}\text { Specific Surface Area } \\
\left(\mathrm{m}^{2} / \mathrm{g}\right)\end{array}$ \\
\hline pGO & $\begin{array}{c}\mathrm{GO} \\
(350 \mathrm{~nm})\end{array}$ & Water & 0.00003 & 2.2 & 2112.45 \\
\hline pGO-JZ30min & $\begin{array}{c}\mathrm{GO} \\
(350 \mathrm{~nm})\end{array}$ & Water & 0.00003 & 2.2 & 1824.47 \\
\hline GO-N-1-JZ30min & $\begin{array}{c}\mathrm{GO} \\
(350 \mathrm{~nm})\end{array}$ & Water & 0.00003 & 2.2 & 1954.47 \\
\hline GO-N-3-JZ30min & $\begin{array}{c}\mathrm{GO} \\
(350 \mathrm{~nm})\end{array}$ & Water & 0.00003 & 2.2 & 1978.14 \\
\hline GO-N-9-JZ30min & $\begin{array}{c}\mathrm{GO} \\
(350 \mathrm{~nm})\end{array}$ & Water & 0.00003 & 2.2 & 2001.17 \\
\hline GO-A-1-JZ30min & $\begin{array}{c}\mathrm{GO} \\
(350 \mathrm{~nm})\end{array}$ & Water & 0.00003 & 2.2 & 2025.31 \\
\hline GO-A-3-JZ30min & $\begin{array}{c}\mathrm{GO} \\
(350 \mathrm{~nm})\end{array}$ & Water & 0.00003 & 2.2 & 2077.97 \\
\hline GO-A-9-JZ30min & $\begin{array}{c}\mathrm{GO} \\
(350 \mathrm{~nm})\end{array}$ & Water & 0.00003 & 2.2 & 2021.15 \\
\hline GO-P-1-JZ30min & $\begin{array}{c}\mathrm{GO} \\
(350 \mathrm{~nm})\end{array}$ & Water & 0.00003 & 2.2 & 2000.47 \\
\hline GO-P-3-JZ30min & $\begin{array}{c}\mathrm{GO} \\
(350 \mathrm{~nm})\end{array}$ & Water & 0.00003 & 2.2 & 2003.14 \\
\hline GO-P-9-JZ30min & $\begin{array}{c}\mathrm{GO} \\
(350 \mathrm{~nm})\end{array}$ & Water & 0.00003 & 2.2 & 2217.63 \\
\hline
\end{tabular}

Note: "JZ30min": resting solution for 30 min before testing.

\subsection{Dispersion State of GO in Sumulated Concrete Pore Solution (SCPS)}

Figure 9 simulates the dispersion state of GO in SCPS, in which the GO to DAs mass ratio is based on the best $\mathrm{GO}$ dispersion in aqueous solutions. It was observed that $\mathrm{GO}$ exhibited appreciably greater agglomeration no matter whether DAs were present or not. When there was no DA, almost all the GO separated from SCPS mixed solution after $30 \mathrm{~min}$, resulting in sedimentation. A few remaining GO suspensions were seen when DAs were present.

The specific surface area of the upper solution of GO in the SCPS after $30 \mathrm{~min}$ of resting is shown in Table 6. The re-agglomeration and sedimentation of GO were observed without dispersing agents. The AEA did not prevent the re-agglomeration of GO in the SCPS, while N-HRWR and P-HRWR could partially prevent GO from re-agglomeration. Further, the effect of P-HRWR was more obvious than that of N-HRWR.

Table 6. Surface parameters and particle size characteristics of GO in simulated concrete pore solution.

\begin{tabular}{cccccc}
\hline Sample & $\begin{array}{c}\text { Sample Style } \\
(\text { Diameter })\end{array}$ & Solvent & $\begin{array}{c}\text { Particle Weight } \\
\text { Concentration }\end{array}$ & $\begin{array}{c}\text { Density of Particle } \\
(\mathbf{g} / \mathbf{m L})\end{array}$ & $\begin{array}{c}\text { Specific Surface Area } \\
\left(\mathbf{m}^{2} / \mathbf{g}\right)\end{array}$ \\
\hline pGO-JZ30min & $\begin{array}{c}\text { GO } \\
(350 \mathrm{~nm})\end{array}$ & Water & 0.00003 & 2.2 & 54.87 \\
\hline GO-N-3-JZ30min & $\begin{array}{c}\mathrm{GO} \\
(350 \mathrm{~nm})\end{array}$ & Water-N & 0.00003 & 2.2 & 215.47 \\
\hline GO-A-9-JZ30min & $\begin{array}{c}\mathrm{GO} \\
(350 \mathrm{~nm})\end{array}$ & Water-A & 0.00003 & 2.2 & 60.47 \\
\hline GO-P-1-JZ30min & $\begin{array}{c}\mathrm{GO} \\
(350 \mathrm{~nm})\end{array}$ & Water-P & 0.00003 & 2.2 & 1205.35 \\
\hline
\end{tabular}



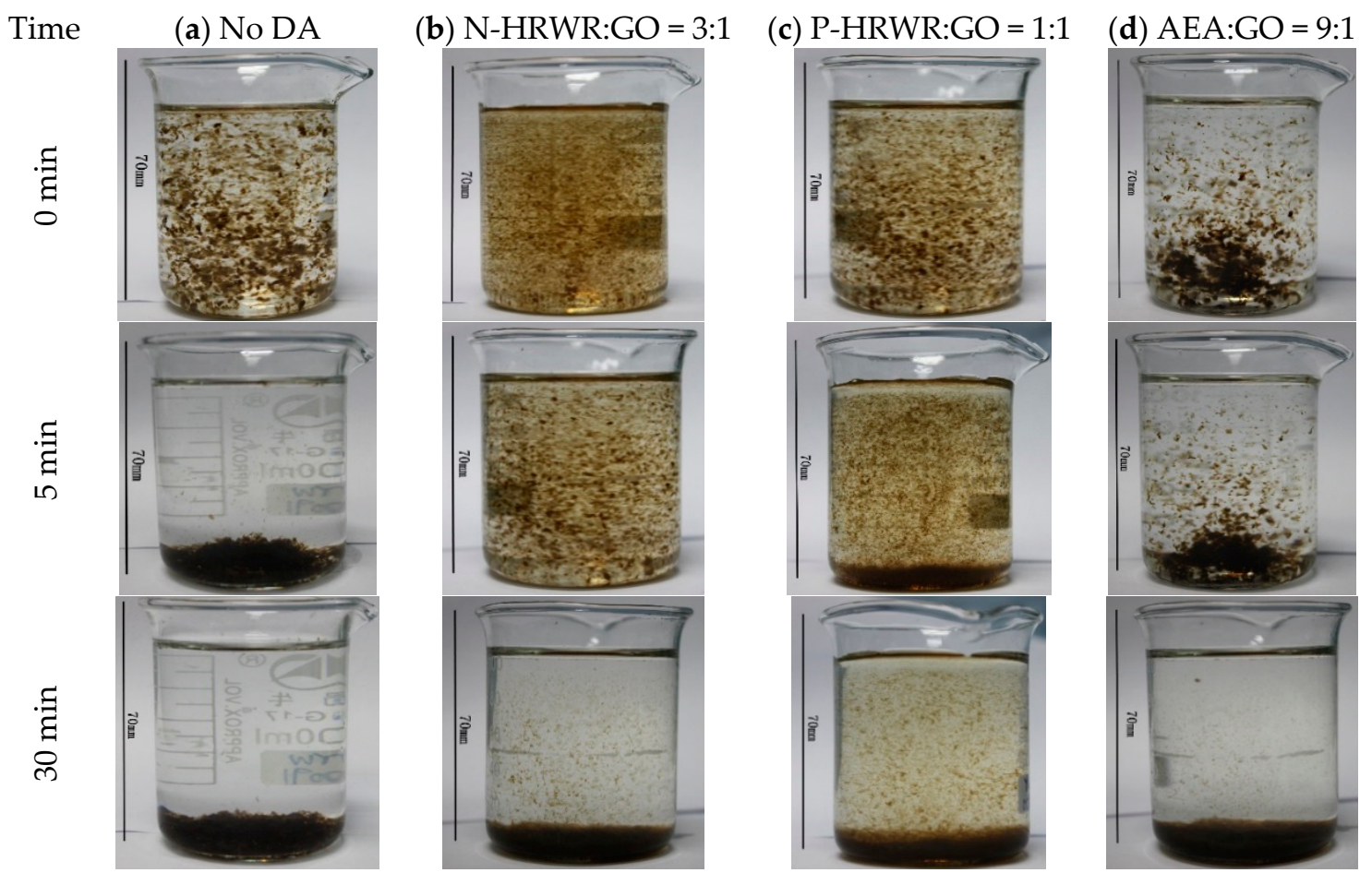

Figure 9. Dispersion state and stability of GO suspensions in SCPS with best DA to GO mass ratio: (a) no DA; (b) N-HRWR; (c) P-HRWR; (d) AEA.

These results provided the evidence that dispersing agents had a positive effect on $\mathrm{GO}$ dispersion in SCPS. During the dispersion process of GO in SCPS solution, cations in SCPS (i.e., $\mathrm{Ca}^{2+}, \mathrm{Na}^{+}$, $\mathrm{K}^{+}$, etc.) competed with $\mathrm{GO}$ for polymers and combined with $\mathrm{GO}$ at the same time, which resulted in sedimentation $[22,55]$.

\subsection{Dispersion State of GO in Cement Paste}

\subsubsection{Effect of Cement Addition on GO Dispersion}

A decrease in dispersion quality of the GO suspensions was observed with increasing cement addition. The separation of the GO agglomerates from solution and then the formation of GO agglomerations was seen when the suspension $\mathrm{pH}$ reached a value of 11 or higher. As shown in Figure $10\left(a_{3}, a_{4}, b_{3}, b_{4}\right)$ the top of the solution became light in color compared to Figure $10\left(a_{1}, a_{2}, b_{1}, b_{2}\right)$ respectively. In Figure $10\left(c_{2}, c_{3}, c_{4}\right)$, the solution turned colorless, and GO uniformly experienced agglomeration and sedimentation. These results agreed with the findings reported by Mendoza and Grunlan et al. [56,57], where a decrease in dispersion as a function of increasing $\mathrm{pH}$ has been reported for CNTs. According to Figure 10a,b, N-HRWR and P-HRWR were conducive to the dispersion of $\mathrm{GO}$ in cement pastes, even when the $\mathrm{pH}$ was greater than 11 compared to AEA. The cement pastes with N-HRWR and P-HRWR still had a majority of GO which did not experience sedimentation, and the solution with N-HRWR (Figure 10 $\left(\mathrm{a}_{4}\right)$ ) was lighter in color at the top than that with P-HRWR (Figure 10( $\left.\mathrm{b}_{4}\right)$ ). Moreover, when the $\mathrm{pH}$ exceeded 11, the GO in the cement pastes added with AEA had experienced full agglomeration and sedimentation (Figure $\left.10\left(\mathrm{c}_{2}, \mathrm{c}_{3}, \mathrm{c}_{4}\right)\right)$. The abovementioned results illustrated that P-HRWR was the most conducive to GO dispersion in cement pastes among the three DAs. Furthermore, these results inferred that homogeneous dispersion in the aqueous solution was not a guarantee of effective dispersion in the cement pastes. 
DAs/GO Ratio

(a)

(b)

(c)

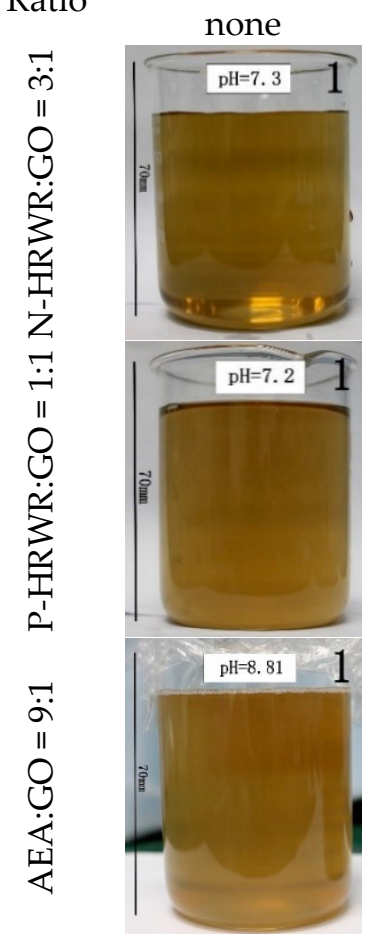

Cement Addition

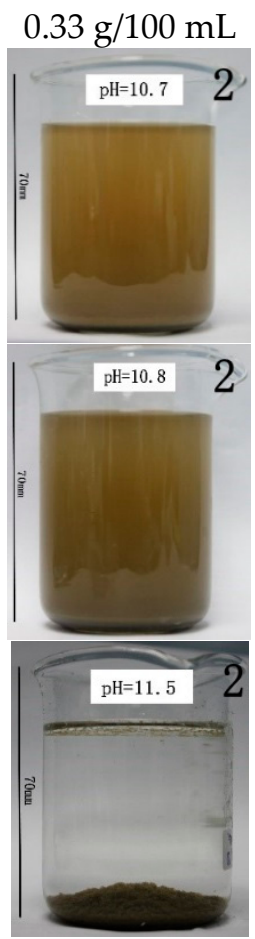

$1 \mathrm{~g} / 100 \mathrm{~mL}$

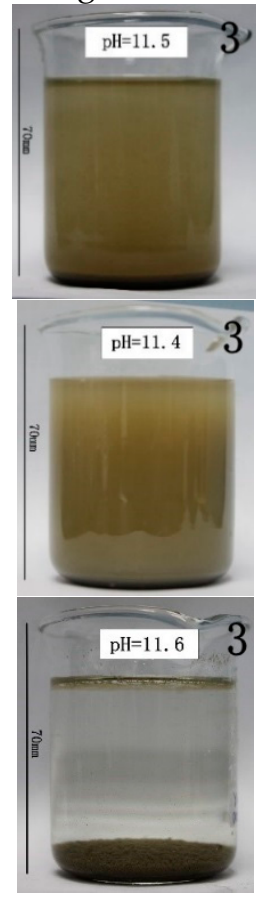

$1.67 \mathrm{~g} / 100 \mathrm{~mL}$

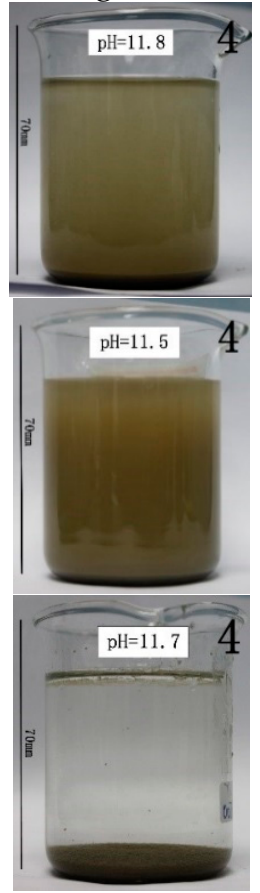

Figure 10. Effect of cement addition on the stability of GO dispersion in aqueous solution at $5 \mathrm{~min}$.

The specific surface area of the upper solution of GO mixed with various dispersants in the cement suspension (cement content of $1.67 \mathrm{~g} / 100 \mathrm{~mL}$ ) was given, as shown in Table 7. It was concluded that the three dispersants of P-HRWR, N-HRWR and AEA had the promoting effect on the dispersion of $\mathrm{GO}$ in cement suspension. Among them, P-HRWR exhibited the best promoting effect, followed by $\mathrm{N}-\mathrm{HRWR}$ and AEA. After the GO suspension with the addition of AEA precipitated, no GO remained in the upper solution, while the upper GO suspension with P-HRWR still contained a large amount of GO.

Table 7. Surface parameters and particle size characteristics of GO in suspension of cement pastes.

\begin{tabular}{|c|c|c|c|c|c|}
\hline Sample & $\begin{array}{c}\text { Sample Style } \\
\text { (Diameter) }\end{array}$ & Solvent & $\begin{array}{l}\text { Particle Weight } \\
\text { Concentration }\end{array}$ & $\begin{array}{l}\text { Density of Particle } \\
\text { (g/mL) }\end{array}$ & $\begin{array}{l}\text { Specific Surface Area } \\
\left(\mathrm{m}^{2} / \mathrm{g}\right)\end{array}$ \\
\hline GO-N-3-C-JZ30min & $\begin{array}{c}\mathrm{GO} \\
(350 \mathrm{~nm})\end{array}$ & Water-N-C & 0.00003 & 2.2 & 515.47 \\
\hline GO-A-9-C-JZ30min & $\begin{array}{c}\mathrm{GO} \\
(350 \mathrm{~nm})\end{array}$ & Water-A-C & 0.00003 & 2.2 & 87.95 \\
\hline GO-P-1-C-JZ30min & $\begin{array}{c}\mathrm{GO} \\
(350 \mathrm{~nm})\end{array}$ & Water-P-C & 0.00003 & 2.2 & 1745.12 \\
\hline
\end{tabular}

\subsubsection{Mechanisms of GO Agglomeration in Cement Paste}

As indicated by the investigations on the dispersion and agglomeration of GO in aqueous solutions, SCPS and cement pastes, the comparisons of multiple DAs indicated that P-HRWR had the most significant effect of avoiding the dispersion and re-agglomeration of GO in cement pastes.

The influence mechanism of P-HRWR on the agglomeration and sedimentation of GO in solutions with different $\mathrm{pH}$ and ion concentrations were examined, as shown in Figure 11. The P-HRWR could be adsorbed onto GO in aqueous solutions and as a result GO was stable to exist in aqueous solutions by virtue of electrostatic interaction and steric hindrance $[27,28]$. N-HRWR realized the stable existence 
of GO via electrostatic interaction and AEA realized that through decreasing the surface tension of solutions.

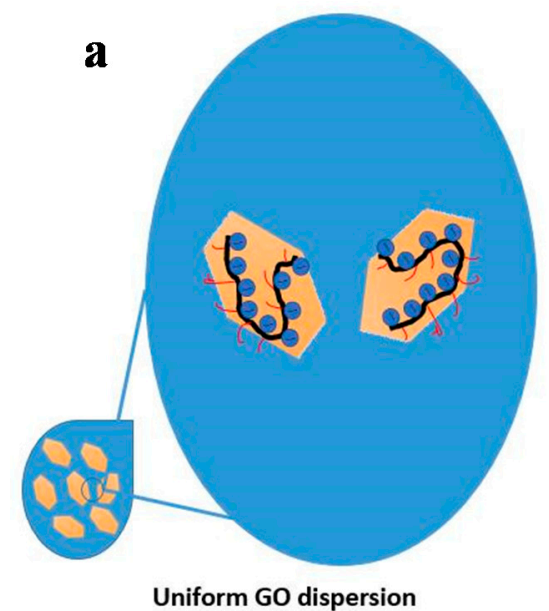

Aqueous Solution

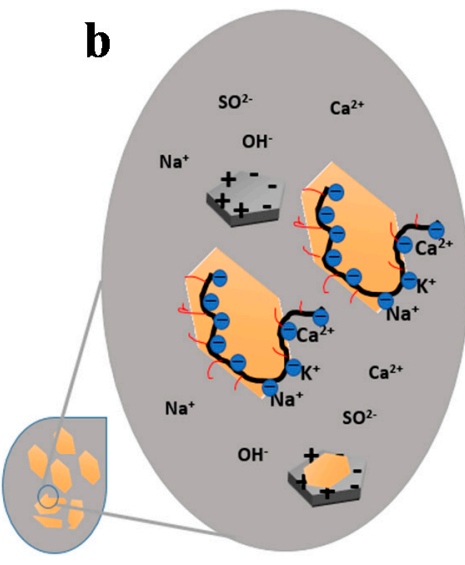

Re-agglomeration and sedimentation of $\mathrm{GO}$ suspension Cement Paste $9<\mathrm{pH}<11$

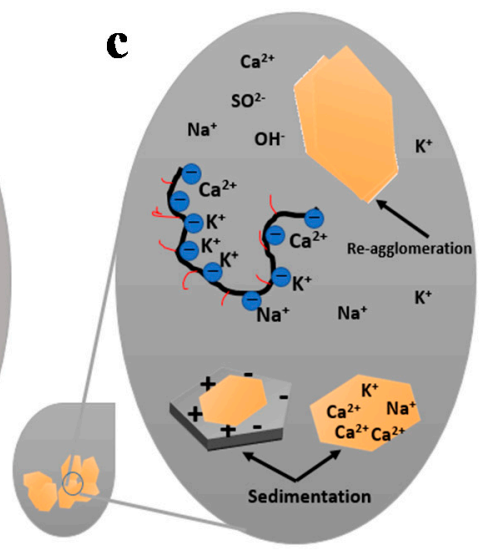

Cement Paste $\mathrm{pH}>11$
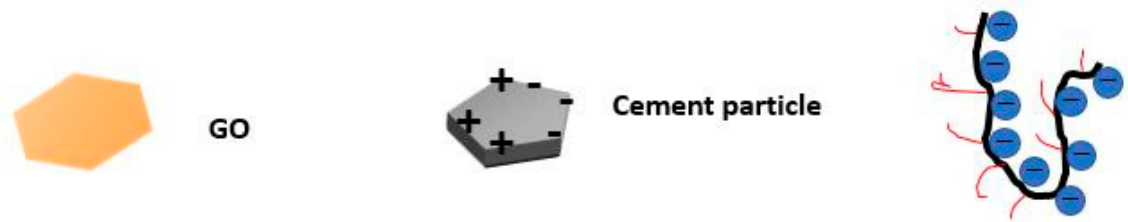

P-HRWR molecule

Figure 11. Schematic representation of the mechanisms of destabilization of the GO dispersion in the (a) aqueous solution; (b) cement paste $9<\mathrm{pH}<11$; and (c) cement paste $\mathrm{pH}>11$ for the P-HRWR.

With the addition and hydration of cement, the $\mathrm{pH}$ of the cement pastes continuously increased (under 11). The ceaseless increase of ions from the cement was due to continuous dissolution of cement particles and undissolved particles containing surface charges could adsorb the GO in solutions, resulting in sedimentation. When the $\mathrm{pH}$ of the solution reached above 11, the presence of cations in the cement pastes could alter the electrostatic layers surrounding the GOs in the P-HRWR assisted suspensions and allowed for the GOs to bind with cations $[22,58]$ and to come into contact or within the distance in which the Van der Waals forces are dominant. Strong interactions between GO and cement particles lead to the sedimentation and re-agglomerates of GO. For the AEA assisted dispersion, the ions present in the cement pastes were thought to increase the surface tension of the solution [52] and negated the effect of the AEA.

\section{Conclusions}

Based on the systematically designed experiments, the dispersion, re-agglomeration and related mechanisms of GO in aqueous solutions, SCPS and suspension of cement pastes were investigated. The following conclusions concerning GO stability and agglomeration were made:

(1) The dispersion of GO in aqueous solutions was positively influenced by P-HRWA, N-HRWA, and AEA, respectively; among the DAs, the AEA provided the most improvement of dispersion in aqueous solutions.

(2) Compared with the dispersion of GO in SCPS and cement pastes, homogeneous dispersion of $\mathrm{GO}$ in aqueous solution did not guarantee uniform dispersion in cement pastes. Although AEA allowed GO to reach the optimum state of dispersion in aqueous solutions, lowering the surface tension of the aqueous solution was AEA's main advantage, which did not exist in the highly alkaline and high ionic strength solution. 
(3) The dual effects of electronic repulsion and steric hindrance of P-HRWR resulted in better GO dispersion in the high alkalinity and high ionic strength of cement paste.

(4) With the increase of ions and $\mathrm{pH}$, the P-HRWR separated from the GO. Thus, GO were absorbed on the surface of the cement particles, and GO sedimentation generated.

Author Contributions: W.-J.L. conceived, designed the experiments and wrote the paper; C.F. performed the experiments and analyzed the data; J.W. and H.L. contributed reagents/materials/analysis tools.

Funding: This research was funded by the National Natural Science Foundations of China [No. 51778368, No. 51578341], and the Shenzhen Overseas High-Caliber Personnel Grant [No. 000095].

Acknowledgments: The authors gratefully acknowledge administrative and technical support given by Guangdong Provincial Key Laboratory of Durability for Marine Civil Engineering.

Conflicts of Interest: The authors declare no conflict of interest.

\section{References}

1. Sanchez, F.; Sobolev, K. Nanotechnology in concrete-A review. Constr. Build. Mater. 2010, 24, $2060-2071$. [CrossRef]

2. Raki, L.; Beaudoin, J.; Alizadeh, R.; Makar, J.; Sato, T. Cement and concrete nanoscience and nanotechnology. Materials 2010, 3, 918-942. [CrossRef]

3. Long, W.J.; Wei, J.J.; Ma, H.Y.; Xing, F. Dynamic mechanical properties and microstructure of graphene oxide nanosheets reinforced cement composites. Nanomaterials 2017, 7, 407. [CrossRef] [PubMed]

4. Senff, L.; Hotza, D.; Llucas, S.; Ferreira, V.M.; Labrincha, J.A. Effect of nano-SiO ${ }_{2}$, and nano-TiO 2 , addition on the rheological behavior and the hardened properties of cement mortars. Mater. Sci. Eng. 2012, 532, 354-361. [CrossRef]

5. Kong, D.; Du, X.; Wei, S.; Zhang, H.; Yang, Y.; Shah, S.P. Influence of nano-silica agglomeration on microstructure and properties of the hardened cement-based materials. Constr. Build. Mater. 2012, 37, 707-715. [CrossRef]

6. Al, J.K.; Shoukry, H. Use of nano-structured waste materials for improving mechanical, physical and structural properties of cement mortar. Constr. Build. Mater. 2014, 73, 636-644. [CrossRef]

7. Pisello, A.L.; D’Alessandro, A.; Sambuco, S.; Rallini, M.; Ubertini, F.; Asdrubali, F.; Materazzi, A.L.; Cotana, F. Multipurpose experimental characterization of smart nanocomposite cement-based materials for thermal-energy efficiency and strain-sensing capability. Sol. Energy Mater. Sol. Cells 2017, 161, 77-88. [CrossRef]

8. Lee, S.J.; You, I.; Zi, G.; Yoo, D.Y. Experimental investigation of the piezoresistive properties of cement composites with hybrid carbon fibers and nanotubes. Sensors 2017, 17, 2516. [CrossRef] [PubMed]

9. Han, B.; Ding, S.; Yu, X. Intrinsic self-sensing concrete and structures: A review. Measurement 2015, 59, 110-128. [CrossRef]

10. Shang, Y.; Zhang, D.; Yang, C.; Liu, Y.; Liu, Y. Effect of graphene oxide on the rheological properties of cement pastes. Constr. Build. Mater. 2015, 96, 20-28. [CrossRef]

11. Li, X.; Korayem, A.; Li, C. Incorporation of graphene oxide and silica fume into cement paste: A study of dispersion and compressive strength. Constr. Build. Mater. 2016, 123, 327-335. [CrossRef]

12. Ghafari, E.; Ghahari, S.; Feng, Y.; Severgnini, F.; Lu, N. Effect of Zinc oxide and Al-Zinc oxide nanoparticles on the rheological properties of cement paste. Compos. Part B 2016, 105, 160-166. [CrossRef]

13. Chithra, S.; Kumar, S.; Chinnaraju, K. The effect of colloidal nano-silica on workability, mechanical and durability properties of high performance concrete with copper slag as partial fine aggregate. Constr. Build. Mater. 2016, 113, 794-804. [CrossRef]

14. Konsta, G.M.; Batis, G.; Danoglidis, P. Effect of CNT and CNF loading and count on the corrosion resistance, conductivity and mechanical properties of nanomodified OPC mortars. Constr. Build. Mater. 2017, 147, 48-57. [CrossRef]

15. Sun, X.; Wu, Q.; Zhang, J.; Yan, Q.; Wu, Y.; Lee, S. Rheology, curing temperature and mechanical performance of oil well cement: Combined effect of cellulose nanofibers and graphene nano-platelets. Mater. Des. 2016, 114, 92-101. [CrossRef] 
16. Wang, Q.; Cui, X.; Wang, J.; Li, S.; Lv, C.; Dong, Y. Effect of fly ash on rheological properties of graphene oxide cement paste. Constr. Build. Mater. 2017, 138, 35-44. [CrossRef]

17. Chuah, S.; Pan, Z.; Sanjayan, J.G.; Wang, C.M.; Duan, W.H. Nano reinforced cement and concrete composites and new perspective from graphene oxide. Constr. Build. Mater. 2014, 73, 113-124. [CrossRef]

18. Long, W.J.; Li, H.D.; Fang, C.L.; Xing, F. Uniformly dispersed and re-agglomerated graphene oxide-based cement pastes: A comparison of rheological properties, mechanical properties and microstructure. Nanomaterials 2018, 8, 31. [CrossRef]

19. Lv, S.; Zhang, J.; Zhu, L.; Jia, C. Preparation of cement composites with ordered microstructures via doping with graphene oxide nanosheets and an investigation of their strength and durability. Materials 2016, 9, 924. [CrossRef] [PubMed]

20. Mohammed, A.; Sanjayan, J.G.; Duan, W.H.; Nazari, A. Incorporating graphene oxide in cement composites: A study of transport properties. Constr. Build. Mater. 2015, 84, 341-347. [CrossRef]

21. Li, W.; Li, X.; Chen, S.; Chen, S.J.; Liu, Y.M.; Duan, W.H.; Shah, S.P. Effects of graphene oxide on early-age hydration and electrical resistivity of Portland cement paste. Constr. Build. Mater. 2017, 136, 506-514. [CrossRef]

22. Gao, Y.; Ren, X.; Tan, X.; Hayat, T.; Alsaedi, A.; Chen, C. Insights into key factors controlling GO stability in natural surface waters. J. Hazard. Mater. 2017, 335, 56-65. [CrossRef] [PubMed]

23. Ma, P.C.; Siddiqui, N.A.; Marom, G.; Kim, J.K. Dispersion and functionalization of carbon nanotubes for polymer-based nanocomposites: A review. Compos. Part A 2010, 41, 1345-1367. [CrossRef]

24. Stephens, C.; Brown, L.; Sanchez, F. Quantification of the re-agglomeration of carbon nanofiber aqueous dispersion in cement pastes and effect on the early age flexural response. Carbon 2016, 107, 482-500. [CrossRef]

25. Parveen, S.; Rana, S.; Fangueiro, R.; Paiva, M.C. Microstructure and mechanical properties of carbon nanotube reinforced cementitious composites developed using a novel dispersion technique. Cem. Concr. Res. 2015, 73, 215-227. [CrossRef]

26. Zhao, L.; Guo, X.L.; Ge, C.; Li, Q.; Guo, L.P.; Shu, X.; Liu, J.P. Investigation of the effectiveness of PC@GO on the reinforcement for cement composites. Constr. Build. Mater. 2016, 113, 470-478. [CrossRef]

27. Lu, L.; Dong, O. Properties of Cement Mortar and Ultra-High Strength Concrete Incorporating Graphene Oxide Nanosheets. Nanomaterials 2017, 7, 187. [CrossRef] [PubMed]

28. Babak, F.; Abolfazl, H.; Alimorad, R.; Parviz, G. Preparation and mechanical properties of graphene oxide: Cement nanocomposites. Sci. World J. 2013, 2014, 1-10. [CrossRef] [PubMed]

29. Rana, S.; Fangueiro, R. A Review on nanomaterial dispersion, microstructure, and mechanical properties of carbon nanotube and nanofiber reinforced cementitious composites. J. Nanomater. 2013, 2013, 1-19. [CrossRef]

30. Bastos, G.; Patiño-Barbeito, F.; Patiño-Cambeiro, F.; Armesto, J. Nano-Inclusions Applied in Cement-Matrix Composites: A Review. Materials 2016, 9, 1015. [CrossRef] [PubMed]

31. Xu, K.; Zhang, Y. Influences of dispersant types and concentrations on stability of graphene water-based slurry. Mater. Rev. 2016, 30, 167-171. [CrossRef]

32. Pourbaix, M.; Franklin, J. Atlas of Electrochemical Equilibria in Aqueous Solutions; Pergamon Press: Oxford, UK; New York, NY, USA, 1966; Volume 1, p. 471.

33. Sahoo, G.; Balasubramaniam, R. On the corrosion behaviour of phosphoric irons in simulated concrete pore solution. Corros. Sci. 2008, 50, 131-143. [CrossRef]

34. Freire, L.; Carmezim, M.J.; Ferreira, M.G.S.; Montemor, M.F. The electrochemical behaviour of stainless steel AISI 304 in alkaline solutions with different $\mathrm{pH}$ in the presence of chlorides. Electrochim. Acta 2011, 56, 5280-5289. [CrossRef]

35. Li, H.; Zhang, M.; Ou, J. Abrasion resistance of concrete containing nano-particles for pavement. Wear 2006, 260, 1262-1266. [CrossRef]

36. Deng, K.; Li, C.; Qiu, X.; Zhou, J.; Hou, Z. Electrochemical preparation, characterization and application of electrodes modified with nickel-cobalt hexacyanoferrate/graphene oxide-carbon nanotubes. J. Electroanal. Chem. 2015, 755, 197-202. [CrossRef]

37. Wang, M.; Wang, R.; Yao, H.; Farhan, S.; Zheng, S.; Du, C. Study on the three dimensional mechanism of graphene oxide nanosheets modified cement. Constr. Build. Mater. 2016, 126, 730-739. [CrossRef] 
38. Sharma, S.; Kothiyal, N. Comparative effects of pristine and ball-milled graphene oxide on physico-chemical characteristics of cement mortar nanocomposites. Constr. Build. Mater. 2016, 115, 256-268. [CrossRef]

39. Kudin, K.; Ozbas, B.; Schniepp, H. Raman spectra of graphite oxide and functionalized graphene sheets. Nano Lett. 2007, 8, 36-41. [CrossRef] [PubMed]

40. Chen, C.; Zhang, Q.; Yang, M.G.; Huang, C.H.; Yang, Y.G.; Wang, M.Z. Structural evolution during annealing of thermally reduced graphene nanosheets for application in supercapacitors. Carbon 2012, 50, 3572-3584. [CrossRef]

41. Ferrari, A.; Robertson, J. Interpretation of Raman spectra of disordered and amorphous carbon. Phys. Rev. B 2008, 61, 14095-14107. [CrossRef]

42. GB50119-2013 Code for Concrete Admixture Application; Ministry of Housing and Urban-Rural Development of the People's Republic of China: Beijing, China, 2013.

43. Łaźniewska, P.B. The methodology for assessing the impact of new generation superplasticizers on air content in self-compacting concrete. Constr. Build. Mater. 2014, 53, 488-502. [CrossRef]

44. Yoshioka, K.; Sakai, E.; Daimon, M.; Kitahara, A. Role of steric hindrance in the performance of superplasticizers for concrete. J. Am. Ceram. Soc. 1997, 80, 2667-2671. [CrossRef]

45. Mindess, S.; Young, J.; Darwin, D. Concrete, 2nd ed.; Prentice Hall: Upper Saddle River, NJ, USA, 2003; ISBN 0130646326.

46. Yan, B.L.; Jiang, L.Z.; Xiao, Z.M.; Liu, C.; Zhang, Q.Y.; Chen, P.; Huo, C.M.; Xi, J.S.; Song, L.C.; Wang, X.; et al. GB/T 175-2007 Common Portland Cement; Standards Press of China: Beijing, China, 2007.

47. Konsta, G.M.; Metaxa, Z.; Shah, S. Highly dispersed carbon nanotube reinforced cement-based materials. Cem. Concr. Res. 2016, 40, 1052-1059. [CrossRef]

48. Metaxa, Z.; Konsta, G.M.; Shah, S. Carbon nanofiber cementitious composites: Effect of debulking procedure on dispersion and reinforcing efficiency. Cem. Concr. Compos. 2013, 36, 25-32. [CrossRef]

49. Konsta, G.M.; Metaxa, Z.; Shah, S. Nanoimaging of highly dispersed carbon nanotube reinforced cement based materials. In Proceedings of the 7th RILEM International Symposium on Fibre Reinforced Concrete, Chennai, India, 17-19 September 2008; pp. 125-131.

50. Zou, B.; Chen, S.J.; Korayem, A.H.; Collins, F.; Wang, C.M.; Duan, W.H. Effect of ultrasonication energy on engineering properties of carbon nanotube reinforced cement pastes. Carbon 2015, 85, 212-220. [CrossRef]

51. Lothenbach, B.; Winnefeld, F. Thermodynamic modelling of the hydration of Portland cement. Cem. Concr. Res. 2006, 36, 209-226. [CrossRef]

52. Wang, Z.; Liu, Q.; Zhu, H.; Liu, H.; Chen, Y.; Yang, M. Dispersing multi-walled carbon nanotubes with water-soluble block copolymers and their use as supports for metal nanoparticles. Carbon 2007, 45, 285-292. [CrossRef]

53. Zhang, C.; Gao, L.; Chen, Y. Fabrication of ceramic oxide-coated SWNT composites by sol-gel process with a polymer glue. J. Nanopart. Res. 2011, 13, 3731-3740. [CrossRef]

54. Chuah, S.; Li, W.; Chen, S.J.; Sanjayan, J.G.; Duan, W.H. Investigation on dispersion of graphene oxide in cement composite using different surfactant treatments. Constr. Build. Mater. 2018, 161, 519-527. [CrossRef]

55. Ren, X.; Li, J.; Tan, X. Impact of $\mathrm{Al}_{2} \mathrm{O}_{3}$ on the aggregation and deposition of graphene oxide. Environ. Sci. Technol. 2014, 48, 5493-5500. [CrossRef] [PubMed]

56. Mendoza, O.; Sierra, G.; Tobón, J. Influence of super plasticizer and $\mathrm{Ca}(\mathrm{OH})_{2}$ on the stability of functionalized multi-walled carbon nanotubes dispersions for cement composites applications. Constr. Build. Mater. 2013, 47, 771-778. [CrossRef]

57. Grunlan, J.; Liu, L.; Regev, O. Weak polyelectrolyte control of carbon nanotube dispersion in water. J. Colloid Interface Sci. 2008, 317, 346-349. [CrossRef] [PubMed]

58. Xing, W.; Yuan, B.; Wang, X.; Hu, Y. Enhanced mechanical properties, water stability and repeatable shape recovery behavior of $\mathrm{Ca}^{2+}$, crosslinking graphene oxide-based nacre-mimicking hybrid film. Mater. Des. 2017, 115, 46-51. [CrossRef]

(c) 2018 by the authors. Licensee MDPI, Basel, Switzerland. This article is an open access article distributed under the terms and conditions of the Creative Commons Attribution (CC BY) license (http:/ / creativecommons.org/licenses/by/4.0/). 